\title{
Efficacy and safety of ultra-low-dose Vagifem (10 mcg)
}

\author{
This article was published in the following Dove Press journal: \\ Patient Preference and Adherence \\ 10 November 201 I \\ Number of times this article has been viewed
}

\author{
Janet A Chollet ${ }^{1,2}$ \\ 'Beth Israel Deaconess Medical \\ Center, Boston, MA, USA; ${ }^{2}$ Pear Tree \\ Pharmaceuticals, Waltham, MA, USA
}

Correspondence: Janet A Chollet ObGyn, Beth Israel Deaconess Medical Center, Boston, and Director and Founder, Pear Tree Pharmaceuticals, Waltham, MA, USA

Tel +I 6172765207

Fax + I61752I6795

Email jchollet@bidmc.harvard.edu

\begin{abstract}
Vulvovaginal atrophy [VVA] is defined as inflammation of the vaginal epithelium due to atrophy secondary to decreased levels of circulating estrogen. There is currently only one approved method for the treatment of VVA, and that is the administration of exogenous estrogens. Overall, the ideal VVA treatment must have benefits, minimize risks, and enhance compliance in the patient while optimizing cost-effectiveness. Unfortunately, of the approximate $25 \%$ of symptomatic women that are thought to seek medical help, the proportion that receives hormone therapy may be small and its duration of use is short. Women have been very reluctant to take hormone therapy due to widely publicized results of the risks associated with hormone therapy. Thus, while menopausal hormone therapy was once accepted as the ideal approach for optimizing changes associated with menopause, prospective randomized clinical trials have challenged that view and have led to a marked decrease in the use of such therapy and increased search for low-dose therapies. This article will highlight the efficacy and safety of recently FDA-approved Vagifem $(10 \mathrm{mcg})$ in treatment of VVA.
\end{abstract}

Keywords: vulvovaginal atrophy, estradiol, menopause

\section{Introduction}

As endogenous estrogen serum levels decline during menopause, the genital tract and other estrogen-dependent tissues gradually undergo atrophic changes. VVA is a thinning of the epithelium secondary to decreased levels of circulating estrogen. Changes in cytology can occur with decreased estrogen levels, leading to increased intermediate and parabasal cells in relation to superficial cells. The loss in estrogendependent cellular maturation in the vagina can result in VVA. The affected tissue becomes more friable, and petechiae, ulcerations, and bleeding may occur after minimal trauma. Blood flow to the vagina is also reduced, leading to a decrease in the transudation, which normally lubricates the vagina during sexual intimacy, resulting in dryness and dyspareunia. The symptoms of VVA are not limited to the menopausal population; symptoms can start before perimenopause, increase during the early perimenopausal period, and further increase in the 2-3 years after menopause. VVA symptoms range in severity from mildly annoying to unbearable. It is progressive and does not spontaneously resolve. Thus, long-term therapy may be necessary to maintain urogenital health.

Currently, women spend more than one-third of their lives in the estrogen-deficient menopausal state. In 2008, there were 50 million American women 50 years or older, and this segment of the population is expected to grow to about 85 million by the year 2014. ${ }^{1}$ According to the North American Menopause Society (NAMS), an 
estimated $10 \%-40 \%$ of menopausal women will experience symptoms related to $\mathrm{VVA}^{2}$ That translates into approximately 16 million women, including 500,000 new patients per year presenting with symptoms of VVA.

Present hormone therapies approved for this condition are administered either systemically or locally in the vagina. The FDA recommends that vaginal formulations are the first choice for the initial management of VVA symptoms. Current recommendations are to continue use of local estrogen therapy for as long as necessary for symptom control. A retrospective study conducted in $>13,000$ women showed that the duration of local estrogen therapy in the real-life setting is about 12 months. ${ }^{3}$ Notwithstanding the above, there seems to be a growing satisfaction among both patients and clinicians with the use of HT to effectively treat VVA. Today, local treatments available to clinicians for VVA are in the form of creams, tablets, and a vaginal ring. Leading estrogens Premarin cream, Estrace, Estring, and Femring are examples (Table 1). These products generally work well and are believed to be safe to use even though vaginal formulations have not been tested in long-term trials to support an assumed more favorable risk-benefit ratio.

Another option for local estrogen therapy is the estradiol vaginal tablet. The tablet containing $25 \mathrm{mcg} 17 \mathrm{~b}$-Estradiol (Vagifem ${ }^{\circledR}$ Novo Nordisk) was first introduced in 1988 and has been shown to provide continuous release of the steroid with transient absorption being significantly reduced after maturation of the epithelium. ${ }^{4}$ The estradiol vaginal tablet can be administered in the vagina through a hydrophilic cellulose-based slow-release tablet. ${ }^{5}$ One tablet is inserted in the vagina once daily for the first 2 weeks, then twice a week thereafter for the purpose of maintenance therapy. Once the tablet comes in contact with vaginal mucosa, a gel layer is formed, allowing diffusion of estradiol.

In general, when compared with vaginal estrogen creams or suppositories, tablets provide a more consistent dose of the hormone, reduce potential leakage, and are associated with greater patient adherence. ${ }^{6,7}$ All treatments provided equivalent relief of the symptoms of VVA based on composite scores of vaginal symptoms (dryness, soreness, and irritation). At weeks 2, 12, and 24, increases in serum estradiol concentrations and suppression of folliclestimulating hormone (FSH) were observed in significantly more patients who were using the vaginal cream than in those using the vaginal tablet $(25 \mathrm{mcg})(P<0.001)$. Further, a retrospective study of patient adherence to vaginal estrogen therapy found that those prescribed vaginal creams discontinued treatment sooner than those given tablets $(50 \%$ discontinuance at 30 days with cream and at 142 days with the tablet; $P<0.001$ ) and filled fewer prescriptions. Better adherence with the tablets occurred despite higher out-ofpocket costs for vaginal tablets.

\section{Efficacy}

Studies with the 25 mcg estradiol vaginal tablet showed significant improvement in VVA symptoms. In a doubleblind, placebo-controlled study, 1612 menopausal patients with urogenital complaints were randomized to receive the Vagifem insert $(25 \mathrm{mcg}$ ) or placebo tablet once a day for a period of 2 weeks, and then twice a week for a total of the 12 months. ${ }^{8}$ The success rates of Vagifem vs placebo on subjective and objective symptoms of VVA were $85.5 \%$ and $41.4 \%$, respectively. A significant improvement of urinary atrophy symptoms was also seen in the Vagifem-treated group as compared with the beginning of the study $(51.9 \%$ vs $15.5 \%, P=0.001)$. It was initially thought that the $25 \mathrm{mcg}$ dose would be necessary for the effective treatment of VVA. In recent years, there has been an effort to use ultra-low-dose vaginal formulations to meet therapeutic goals, as an alternative to traditional regimens.

There were initial findings from clinical trials that a lower-dose tablet containing $10 \mathrm{mcg}$ may also be effective for the relief of VVA symptoms. In a double-blind, randomized, parallel-group study, 58 menopausal women were treated with $25 \mathrm{mcg}$ or $10 \mathrm{mcg}$ estradiol vaginal tablet for 12 weeks. $^{9}$ In each treatment group, participants demonstrated significant improvement in vaginal maturation values over baseline at weeks 1 and $2(P<0.001)$, and at week $12(P<0.01)$. At all points, mean maturation values were comparable between groups.

Table I Current hormonal therapies for vulvovaginal atrophy

\begin{tabular}{lllll}
\hline Drug name & Drug category & Form and delivery & Dosage & Pharmaceutical company \\
\hline Premarin vaginal cream & Estrogen derivative & Vaginal cream & $0.625 \mathrm{mg}$ conjugated estrogens & Wyeth \\
Estrace $^{\circledR}$ & Estrogen derivative & Vaginal cream & $0.01 \%$ estradiol cream & Warner Chilcott \\
Estring $^{\circledR}$ & Estrogen derivative & Vaginal ring & $7.5 \mathrm{mcg} 17 \beta$ estradiol & Pfizer \\
*Femring $^{\circledR}$ & Estrogen derivative & Vaginal ring & $0.05 \mathrm{mg}$ or 0.1 mg estradiol & Warner Chilcott \\
\hline
\end{tabular}

Note: *Femring ${ }^{\circledR}$ is FDA-approved for both local and systemic hormone therapy. 
In a multi-center, randomized, double-blind, parallelgroup study, 230 menopausal women received treatment with $25 \mathrm{mcg}$ or $10 \mathrm{mcg}$ vaginal tablet estradiol or placebo for 12 weeks. ${ }^{10}$ After 12 weeks, the percentage of participants with $\mathrm{pH}<5$ were $51 \%, 39 \%$, and $21 \%$ in the $25 \mathrm{mcg}$, $10 \mathrm{mcg}$, and placebo group, respectively. The vaginal cytology results showed significant increases at week 2 and 7 in the percentage of superficial cells for participants in the $25 \mathrm{mcg}$ group as compared to placebo. Maturation values for the $10 \mathrm{mcg}$ group were significantly higher than for the placebo at week $2(P<0.001)$ and were not significantly different from the improved values for the $25 \mathrm{mcg}$ group at any time point. Vaginal tablets with $25 \mathrm{mcg}$ and $10 \mathrm{mcg}$ improved VVA by decreasing vaginal $\mathrm{pH}$ and increasing maturation of the vaginal epithelium. These improvements were greater with the $25 \mathrm{mcg}$ than with the $10 \mathrm{mcg}$ which was to be expected.

In a pivotal phase, menopausal women $(\mathrm{N}=309)$ were randomly assigned to the $10 \mathrm{mcg}$ estradiol vaginal tablet or placebo for 52 weeks in a double-blind study. ${ }^{11}$ At 12 weeks, the change from baseline for 10 mcg compared with placebo showed a significant improvement in superficial cells $(13.2 \%$ vs $3.8 \%, P<0.001)$, decreasing the percentage of parabasal cells $(-37.0 \%$ vs $-93 \%, P<0.001)$, decreasing vaginal $\mathrm{pH}$ score $(-1.3$ vs $-0.4, P<0.001)$, and most bothersome symptom score $(-1.23$ vs $-0.87, P=0.003)$. Also, for percentage improvement in the superficial cells and vaginal $\mathrm{pH}$, treatment effects were statistically different from placebo after 2 weeks of treatment. However, for the most bothersome symptoms, treatment effect became apparent after 4 weeks and reached statistical significance at 8 weeks of therapy. All treatment effects continued to be significant up through 52 weeks of treatment.

\section{Safety}

The endometrial safety of the $10 \mathrm{mcg}$ estradiol vaginal tablet was evaluated in 336 women. The baseline endometrial thickness was $2.04 \mathrm{~mm}$ as determined by ultrasound compared with $1.94 \mathrm{~mm}$ after 52 weeks. There was no evidence of increased endometrial thickness after 1 year of treatment for VVA in menopausal women. ${ }^{12}$ In an additional safety study, endometrial biopsy data from participants using the $10 \mathrm{mcg}$ estradiol vaginal tablet $(\mathrm{N}=205)$ in a randomized, double-blind, placebo-controlled trial were pooled with the data from an open-label endometrial safety trial $(\mathrm{N}=336) .{ }^{13}$ Patients received active treatment for 52 weeks. A total of 443 participants had an endometrial biopsy performed at week 52. In total, two events of hyperplasia and carcinoma were reported in 386 evaluable biopsy samples (incidence rate $0.52 \%$ per year). The reported prior incidence rate of endometrial hyperplasia and carcinoma in menopausal women is $0 \%-1 \%$. These results were well within the confidence interval bounds established by the FDA (one-sided 95\% confidence interval: $0 \%-1.62 \%$, upper bound below the $4 \%$ rate) and the European Medicines Agency (two-sided 95\% confidence interval: $0.06 \%-1.86 \%$, upper bound below $2 \%$ rate) for endometrial safety. The author concluded that there was no increased risk of endometrial hyperplasia or carcinoma in menopausal women undergoing treatment for VVA with the $10 \mathrm{mcg}$ estradiol vaginal tablet after 1 year of therapy.

Other safety events reported in 5\% or more of women treated with estradiol $10 \mathrm{mcg}$ vaginal tablet for 1 year included back pain ( $7 \%$ vs $2 \%$ for placebo), diarrhea $(5 \%$ vs $0 \%$ ), vulvovaginal mycotic infection ( $8 \%$ vs $3 \%$ ), and vulvovaginal pruritus ( $8 \%$ vs $2 \%$ ).

Vaginal estradiol tablet provides localized effects without significant systemic absorption. In a double-blind, randomized, parallel-group study, 58 menopausal women were treated with $25 \mathrm{mcg}$ or $10 \mathrm{mcg}$ estradiol vaginal tablet for 12 weeks. Systemic absorption of estradiol was noted to be low and stable over time. ${ }^{14}$ Furthermore, in another assessment, during 12 weeks administration, $10 \mathrm{mcg}$ vaginal tablets resulted in at least $50 \%$ lower mean estradiol concentrations than with the $25 \mathrm{mcg}$ dose within 24 hours after dosing. ${ }^{15}$ After administering the $25 \mathrm{mcg}$ dose, mean estradiol levels during the first 2 weeks exceeded the published referenced range for menopausal women, while, with the $10 \mathrm{mcg}$ dose, mean estradiol levels remained in the menopausal range indicating minimal estradiol absorption. After 1 year of treatment with the $10 \mathrm{mcg}$ vaginal tablet, levels of estrogen in the body were within the menopausal range (2.44-12.08 pg/mL). Overall, the profile of systemic exposure to estradiol was similar to the $25 \mathrm{mcg}$ tablet, but absolute values were higher than with the lower dose tablet.

Although systemic absorption with local estrogen absorption is likely to be minimal, it is unknown whether this limited absorption will affect outcomes in women with hormone-dependent breast cancer. Currently, a clinical trial $(\mathrm{N}=60)$ is underway to determine serum estradiol levels in menopausal women with breast cancer receiving adjuvant aromatase inhibitors (AIs) and low-dose vaginal estradiol tablet $(10 \mathrm{mcg}) .{ }^{16}$ The primary outcome is to determine the change in estradiol and follicle stimulating hormone (FSH) from baseline to 12 weeks in menopausal women receiving either letrozole or anastrozole treatment with vaginal estradiol (10 mcg). Secondary outcomes will describe the patterns of 
estradiol and FSH levels over the 24-week study period; to compare the rise in estradiol during treatment with the vaginal estradiol to see if there is a difference between AIs; and to compare the patients' Female Sexual Function Index score and menopause quality of life questionnaire at baseline, week 12, and week 24. All in all, any rise above baseline serum estradiol may have an impact on AI efficacy.

In November 2009, the FDA approved the $10 \mathrm{mcg}$ estradiol vaginal tablet formulation (Vagifem) for the treatment of VVA in menopausal women. Estradiol vaginal tablets previously were approved in a $25 \mathrm{mcg}$ formulation in the United States and European Union. The company discontinued the sale of Vagifem $25 \mathrm{mcg}$ in the United States on July $30,2010 .{ }^{17}$

\section{Conclusion}

Interest in the potential for lower systemic hormonal exposure with the use of local vaginal estrogen therapy has grown since the results of the Women's Health Initiative were made public almost 10 years ago. When HT is considered solely for VVA, then local therapy is recommended. Vaginal administration of an ultra-low-dose estrogen provides sufficient estrogen to relieve symptoms and reverse the atrophic changes associated with menopause, with the added benefit of limited systemic absorption.

\section{Disclosure}

The author reports no conflict of interest in this work.

\section{References}

1. Wolters Kluwer. Standard Population Data. 2008. Available at: http:// www.wolterskluwer.com. Accessed November 8, 2011.

2. North American Menopause Society. The role of local vaginal estrogen for treatment of vaginal atrophy in postmenopausal women: 2007 position statement of the North American Menopausal Society. Menopause. 2007;14(3 Pt 1):355-369.

3. Shulman LP, Portman DJ, Lee WC, et al. A retrospective managed care claims data analysis of medication adherence to vaginal estrogen therapy: implications for clinical practice. $J$ Womens Health (Larchmt). 2008;17(4):569-578.
4. Nilsson K, Heimer G. Low-dose oestradiol in the treatment of urogenital oestrogen deficiency-a pharmacokinectic and pharmacodynamics study. Maturitas. 1992;15(2):121-127.

5. Mainini G, Scaffa C, Rotondi M, Messalli EM, Quirino L, Ragucci A. Local estrogen replacement therapy in postmenopausal atrophic vaginitis: efficacy and safety of low-dose 17b-estradiol vaginal tablets. Clin Exp Obstet Gynecol. 2005;32(2):111-113.

6. Rioux JE, Devlin C, Gelfand MM, Steinburg WM, Hepburn DS. $17 \mathrm{~b}$-estradiol vaginal tablet versus conjugated equine estrogen vaginal cream to relieve menopausal atrophic vaginitis. Menopause. 2000; 7(3):156-161.

7. Dugal R, Hesla K, Sørdal T, Aase KH, Lilleeidet O, Wickstrøm E. Comparison of usefulness of estradiol vaginal tablets and estriol vagitories for treatment of vaginal atrophy. Acta Obstet Gynecol Scand. 2000;79:292-297.

8. Simunić V, Banović I, Ciglar S, Jeren L, Pavicić Baldani D, Sprem M. Local estrogen treatment in patients with urogenital symptoms. Int $J$ Gynaecol Obstet. 2003;82(2):187-197.

9. Notelovitz M, Funk S, Nanavati N, Mazzeo N. Estradiol absorption from vaginal tablets in postmenopausal women. Obstet Gynecol. 2002;99(4):556-562.

10. Bachmann G, Rogerio A, Gut R, Nachtigall L, Notelovitz M. Efficacy of low-dose estradiol vaginal tablets in the treatment of atrophic vaginitis: a randomized controlled trial. Obstet Gynecol. 2008;111(1): $67-76$.

11. Simon J, Nachtigall L, Gut R, Lang E, Archer D, Utian W. Effective treatment of vaginal atrophy with an ultra-low-dose estradiol vaginal tablet. Obstet Gynecol. 2008;112(5):1053-1060.

12. Ulrich LS, Naessen T, Elia D, Goldstein JA, Eugster-Hausmann M; VAG1748 trial investigators. Endometrial safety of ultra-low-dose Vagifen $10 \mathrm{mcg}$ in postmenopausal women with vaginal atrophy. Climacteric. 2010;13(3):228-237.

13. Simon J, Nachtigall L, Ulrich LG, Eugster-Hausmann M, Gut R. Endometrial safety of ultra-low-dose estradiol vaginal tablets. Obstet Gynecol. 2010;116(4):876-883.

14. Notelovitz M, Funk S, Nanavati N, Mazzeo N. Estradiol absorption from vaginal tablets in postmenopausal women. Obstet Gynecol. 2002; 99(4):556-562.

15. Eugster-Hausmann M, Waitzinger J, Lehnick D. Minimized estradiol absorption with ultra-low-dose 10 microg 17 beta-estradiol vaginal tablets. Climacteric. 2010;13(3):219-227.

16. Mayo Clinic. A Trial to Evaluate the Efficacy of Low Dose Vaginal Estrogens in the Treatment of Atrophic Vaginitis. In: ClinicalTrials.gov [Internet]. Bethesda, MD: National Library of Medicine (US). 2008. Available from: http://clinicaltrials.gov/ct2/show/NCT00816556. NLM Identifier: NCT00816556.

17. Novo Nordisk. Vagifem $10 \mathrm{mcg}$ to replace Vagifem $25 \mathrm{mcg}$ formulation for atrophic vaginitis due to menopause. Available at: http://press. novonordisk-us.com/index.php?s=43\&item=252. Accessed October 7, 2010.
Patient Preference and Adherence

\section{Publish your work in this journal}

Patient Preference and Adherence is an international, peer-reviewed, open access journal focusing on the growing importance of patient preference and adherence throughout the therapeutic continuum. Patient satisfaction, acceptability, quality of life, compliance, persistence and their role in developing new therapeutic modalities and compounds to

\section{Dovepress}

optimize clinical outcomes for existing disease states are major areas of interest. This journal has been accepted for indexing on PubMed Central. The manuscript management system is completely online and includes a very quick and fair peer-review system. Visit http://www.dovepress.com/ testimonials.php to read real quotes from published authors. 